\title{
GERMINAÇÃO E CRESCIMENTO INICIAL DA MUDA DE ORELHA-DE- MACACO (Enterolobium contortisiliqunn (Vell.) Morong): EFEITO DE TRATAMENTOS QUÍMICOS E LUMINOSIDADE ${ }^{1}$
}

Silvana de Paula Quintão Scalon², Rosilda Mara Mussury³, Ana Amélia Gomes³, Keila Aparecida Silva ${ }^{4}$, Fabiana Wathier ${ }^{4}$ e Homero Scalon Filho ${ }^{5}$

\begin{abstract}
RESUMO - Avaliou-se o potencial de germinação das sementes de orelha-de-macaco após os tratamentos prégerminativos e o crescimento inicial das mudas tratadas com ácido giberélico (GA) e sombreamento. As sementes receberem os seguintes tratamentos de escarificação + embebição: 1) $\mathrm{H}_{2} \mathrm{SO}_{4} / 5$ ‘ ; 2) $\mathrm{H}_{2} \mathrm{SO}_{4} / 5^{\text {‘ }}+$ água/24 h; 3)

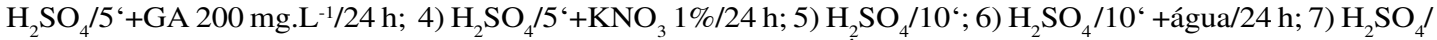
$\left.10^{\circ}+\mathrm{GA} 200 \mathrm{mg} \cdot \mathrm{L}^{-1} / 24 \mathrm{~h} ; 8\right) \mathrm{H}_{2} \mathrm{SO}_{4} / 10^{\circ}+\mathrm{KNO}_{3} 1 \% / 24 \mathrm{~h}$; 9) Ấgua 24/ h; e 10) testemunha e a semeadura em casa de vegetação. As mudas foram tratadas com GA 0, 50 e $100 \mathrm{mg} . \mathrm{L}^{-1} \mathrm{e}$ mantidas em sombrite $50 \%$ de sombra e a pleno sol até 180 dias após a semeadura. Não se observou germinação na testemunha e na imersão apenas em água. A emergência, TMPA, MSR e MSPA não variaram entre os tratamentos de escarificação (média de 89\%; 6,55 cm; 0,08 g; e 1,8 g; e o TMR em $\mathrm{H}_{2} \mathrm{SO}_{4} / 10^{\star}+\mathrm{KNO}_{3}(13,73 \mathrm{~cm})$. Com base nesses resultados, as sementes podem ser escarificadas por 10' $\mathrm{com}_{2} \mathrm{SO}_{4}$ As mudas a pleno sol apresentaram maior altura (51,94 cm), MSF (3,6 g), MSPA (7,21 g), MSR (4,27 g) e MST (11,59 g). A TAL, RAF e TCR não variaram entre os níveis de luz e tratamentos com GA. As doses de giberelina estudadas não alteraram o crescimento das mudas.
\end{abstract}

Palavras-chave: Semente, escarificação, sombreamento e ácido giberélico.

\section{GERMINATION AND INITIAL GROWTH OF 'ORELHA DE MACACO” (Enterolobium contortisiliqunn (Vell.) Morong) SEEDLINGS: EFFECT OF CHEMICAL TREATMENTS AND LIGHT}

\begin{abstract}
The germination potential of 'Orelha de macaco" seeds after pre-germination treatments and the initial growth of seedlings treated with gibberellic acid (GA) and shade were evaluated. Seeds received the following treatments of scarification and imbibition: 1) $\mathrm{H}_{2} \mathrm{SO} / 5$ minutes; 2) $\mathrm{H}_{2} \mathrm{SO} / 5$ minutes + water/ 24 hours; 3) $\mathrm{H}_{2} \mathrm{SO}_{4} / 10$ minutes $+\mathrm{GA} 200 \mathrm{mg} . \mathrm{L}^{-1} / 24$ hours; 4) $\mathrm{H}_{2} \mathrm{SO}_{4} / 5$ minutes $+\mathrm{KNO}_{3} 1 \% / 24$ hours; 5) $\mathrm{H}_{2} \mathrm{SO}_{4} / 10$ minutes; 6) $\mathrm{H}_{2} \mathrm{SO}_{4} / 10$ minutes + water/24 hours; 7) $\mathrm{H}_{2} \mathrm{SO}_{4} / 10$ minutes + GA 20Omg.L-1/24 hours; 8) $\mathrm{H}_{2} \mathrm{SO}_{4} 110$ minutes $+\mathrm{KNO}_{3} 1 \% / 24$ hours; 9) water 24 hours; 10) control and sowing was carried out in green house. Seedlings were treated with GA 0.50 and $100 \mathrm{mg} . \mathrm{L}^{-1}$ and kept under $50 \%$ shade and in full sun up to 180 days after sowing. There was no germination in the control and for imbibition only in water. Emergence, LR, DMR and DMAP did not vary between scarification treatments ( $89 \%$ mean, $6.55 \mathrm{~cm}, 0.08$ $g$ and $1.8 \mathrm{~g}, \mathrm{LR}$ in $\mathrm{H}_{2} \mathrm{SO}_{4} 10$ minutes $+\mathrm{KNO}_{3}$ (13.73). Based on these results, seeds can be scarified for 10 minutes with $\mathrm{H}_{2} \mathrm{SO}_{4}$. Seedlings in full sun showed the highest height $\left.(51.94 \mathrm{~cm}), \mathrm{DML}(3.6 \mathrm{~g}), \mathrm{DMAP} 97.21 \mathrm{~g}\right)$, $D M R(4.27 \mathrm{~g})$ and TDM (11.59g). ALR, LAR and RGR did not vary between light intensity and GA treatments. The studied doses of gibberellin did not alter seedling growth.
\end{abstract}

Keywords: Seed, scarification, shade and gibberellic acid.

\footnotetext{
${ }^{1}$ Recebido em 10.12.2004 e aceito para publicação em 05.04.2006.

${ }^{2}$ Universidade Federal de Mato Grosso do Sul/DCA, Rodovia Dourados-Ithaum, km 12, Bairro Rural, 79804-970 - Dourados, MS

${ }^{3}$ Centro Universitário da Grande Dourados/UNIGRAN.

${ }^{4}$ Curso de Ciências Biológicas/UNIGRAN

${ }^{5}$ Universidade Estadual de Mato Grosso do Sul. E-mail: <sscalon@ @eud.ufms.br>.
} 


\section{INTRODUÇÃO}

O uso de espécies arbóreas nativas em programas de reflorestamento com manejo sustentável ou para arborização urbana vem se intensificando nos últimos anos. Entretanto, muitas espécies apresentam mecanismos de dormência, dificultando o planejamento dos viveiristas para a obtenção de mudas. A dormência das sementes pode ser vantajosa para a perpetuação das espécies, ampliando a possibilidade de estabelecimento de novos indivíduos ou colonização de áreas por distribuir a germinação no tempo, porém ela pode representar grande problema quando se considera a exploração vegetal (CARVALHO e NAKAGAWA, 2000; ZAIDAN e BARBEDO, 2004).

A impermeabilidade do tegumento à água é o principal mecanismo de manutenção de baixos teores de água no interior da semente, o que evita o metabolismo mais intenso, reduz a respiração e, assim, diminui o consumo de reservas, fundamentais para a germinação e o crescimento inicial da plântula (ZAIDAN e BARBEDO, 2004). Os métodos a serem empregados para quebrar essa dormência deverão promover aberturas no tegumento, permitindo a embebição, como ocorre com a escarificação, que pode ser realizada com o auxílio de materiais cortantes ou abrasivos e agentes químicos (ácidos fortes, nitrato de potássio, reguladores de crescimento e solventes orgânicos).

Os ácidos como o ácido sulfúrico, quando em contato com os tegumentos duros da semente, podem levar à ruptura da testa, facilitando a embebição e trocas gasosas. Tem sido amplamente utilizado em sementes de espécies arbóreas como Bowdichia virgilioides (sucupira-preta), Indigofera suffruticosa (anileira), Cassia excelsa (sabiá), Mimosa caesalpiniaefolia (sabiá) (JELLER e PEREZ, 1999; GARCIA et al., 2000; BRUNO et al., 2001; SMIDERLE e SOUZA, 2003).

O nitrato de potássio pode ser empregado na quebra de dormência, uma vez que os receptores do nitrato e proteínas presentes na membrana plasmática interagem com os fitocromos. Dessa interação inicia-se uma cascata de transdução de sinais que envolve a síntese de giberelina e ativação do metabolismo voltado para o alongamento embrionário (HILHORST, 1998). O nitrato de potássio foi empregado na quebra de dormência de Erechtites valerianaefolia (capiçova) (ZAYAT e RANAL, 1997). Em sementes de Muntingia calabura (calabura) tratadas com $\mathrm{KNO}_{3}$, observou-se maior porcentagem de germinação e IVG, em comparação com os demais tratamentos (LOPES et al., 2002).

As giberelinas promovem a síntese de enzimas envolvidas no enfraquecimento dos tegumentos como endo-b-manases e expansinas e enzimas hidrolíticas de reserva nutritiva contida no endosperma como aamilase. Esses eventos estão relacionados ao alongamento embrionário e à protrusão da radícula (BEWLEY e BLACK, 1994, 1997). Promovem a divisão e o alongamento celulares e elevam a plasticidade da parede celular, atuando preferencialmente em células jovens e meristemáticas, devido à orientação transversal das microfibrilas de celulose (KERBAUY, 2004). Elas podem atuar silenciando genes da dormência ou como agentes de quebra da dormência (KOORNNEEF et al., 2002; PENG e HARBERD, 2002). São escassos os trabalhos sobre a utilização de fitorreguladores em espécies arbóreas e arbustivas. Nas mudas, os efeitos das giberelinas aparecem no alongamento do caule, comprimento dos internódios, área foliar e acúmulo de matéria seca (STEFANINI et al., 2002). Erig et al. (2001) observaram efeito benéfico do ácido giberélico no crescimento de mudas de Annona squamosa (frutado-conde.) e sugeriam que sua utilização pode diminuir o tempo necessário para a produção de porta-enxertos. Esses autores verificaram em sua revisão que a dose de GA 100 mg.L L $^{-1}$ elevou o crescimento das plantas de Citrus reshni T. x Poncirus trifoliata, Citrus limettioides T. e Citrus aurantium L. Entretanto, as espécies respondem diferentemente a determinados tipos de giberelinas.

Observou-se que a maioria das dicotiledôneas e algumas monocotiledôneas e coníferas crescem mais rápido quando tratadas com determinadas giberelinas. Em Pinaceae, algumas espécies respondem pouco ao $\mathrm{GA}_{3}$, mas crescem em resposta a uma mistura de $\mathrm{GA}_{4}+\mathrm{GA}_{7}$ (KERBAUY, 2004).

Segundo Magalhães (1986), citado por Stefanini et al. (2002), a análise de crescimento relaciona as condições morfológicas da planta ao longo do seu desenvolvimento. É um método que pode ser utilizado para investigação do efeito dos fenômenos ecológicos sobre o crescimento, como adaptabilidade das espécies em diferentes ecossistemas, efeitos de competição, diferenças genotípicas da capacidade produtiva e influência das práticas agronômicas. 
Portela et al. (2001), em sua revisão, observaram que cada espécie florestal apresenta exigência luminosa própria para seu desenvolvimento e que as plântulas podem aproveitar e se desenvolver melhor em locais com alta intensidade luminosa - como acontece nas grandes clareiras - e outras em sombreamento, como nos sub-bosques.

Mudas de Goupia glabra (cupiúba) não podem ser produzidas a pleno sol, em que ocorre alta mortalidade, porém todas as variáveis de crescimento aumentam com o sombreamento (DANIEL et al., 1994). Avaliando a altura, comprimento de raiz e peso de matéria seca da raiz de mudas de espécies arbóreas sob 0,30, 50 e $75 \%$ de sombreamento, Portela et al. (2001) observaram que as mudas de Clitoria fairchildiana (sombreiro) apresentaram maior altura e peso de matéria seca de raiz a pleno sol, enquanto em para Peltophorum dubium (canafístula) não se observou diferença significativa na altura e comprimento da raiz, embora apresentasse maior peso de matéria seca de raiz a pleno sol.

A sobrevivência das mudas de Bombacopsis glabra (castanha-do-maranhão), o diâmetro do caule, a área foliar, clorofilas $a$ e $b$, TCR, TAL e RAF não variaram significativamente a 30 e $50 \%$ de sombreamento e a pleno sol. As mudas crescidas sob $50 \%$ de sombra apresentaram maior altura, maior clorofila total e menor relação $a / b$, apresentando bom desenvolvimento sob pleno sol e tolerando sombreamentos de 30 e $50 \%$ (Scalon et al., 2003).

Os objetivos deste trabalho foram avaliar a emergência das sementes de orelha-de-macaco no campo após tratamentos pré-germinativos e o crescimento inicial das mudas em diferentes condições de luminosidade e tratamentos com ácido giberélico.

\section{MATERIAL E MÉTODOS}

As sementes foram colhidas em árvores localizadas na Cidade de Dourados, MS, situada a $22^{\circ} 13^{\prime} 16^{\prime \prime}$ de latitude sul e $54^{\circ} 48^{\prime \prime} 2^{\prime \prime}$ de longitude oeste e altitude média de $452 \mathrm{~m}$. O clima é classificado como Cwa (MATO GROSSO DO SUL, 1990) sendo a precipitação média anual de $1500 \mathrm{~mm}$, com temperatura média durante o ano de $22^{\circ} \mathrm{C}$.

\section{Teste de germinação}

As sementes foram armazenadas em embalagens de papel e mantidas na temperatura ambiente durante cinco meses. Após esse período, foram escarificadas, recebendo os seguintes tratamentos pré-germinativos: 1) $\mathrm{H}_{2} \mathrm{SO}_{4} / 5^{`}$; 2) $\mathrm{H}_{2} \mathrm{SO}_{4} / 5^{\text {‘ }}+$ embebição em água/24 h; 3) $\mathrm{H}_{2} \mathrm{SO}_{4} / 5^{\circ}+$ embebição em ácido giberélico 200 mg. $\mathrm{L}^{-1} / 24 \mathrm{~h}$; 4) $\mathrm{H}_{2} \mathrm{SO}_{4} / 5^{`}+$ embebição em nitrato de potássio $1 \% / 24 \mathrm{~h}$; 5) $\mathrm{H}_{2} \mathrm{SO}_{4} / 10$; ; 6) $\mathrm{H}_{2} \mathrm{SO}_{4} / 10^{`}$ + embebição em água/24 h; 7) $\mathrm{H}_{2} \mathrm{SO}_{4} / 10^{`}+$ embebição em ácido giberélico $200 \mathrm{mg} . \mathrm{L}^{-1} / 24 \mathrm{~h}$; 8) $\mathrm{H}_{2} \mathrm{SO}_{4} / 10^{‘}+$ embebição em nitrato de potássio $1 \% / 24 \mathrm{~h}$; 9) Água/24 h; 10) Testemunha. A semeadura foi em bandejas de isopor com células de $3 \times 3 \mathrm{~cm}$ contendo Plantmax como substrato e mantidas na casa de vegetação da UFMS.

O experimento foi conduzido em delineamento inteiramente casualizado com quatro repetições de 20 sementes. Foram avaliados a porcentagem de emergência (E\%), o índice de velocidade de emergência (IVE) segundo Popinigis (1985), o tamanho da maior raiz (TMR) e da parte aérea (TMPA) e a massa seca de raiz (MSR) e da parte aérea (MSPA). Os dados foram analisados pelo teste $\mathrm{F}$, sendo as médias comparadas pelo teste de Tukey a $1 \%$ de probabilidade.

\section{Teste de crescimento inicial da muda}

As plântulas aos 15 dias após a germinação foram transplantadas para embalagens plásticas de 30 x 12 $\mathrm{cm}$ contendo terra + areia + esterco curtido de curral (2:2:1) e mantidas sob sombrite $50 \%$ durante sete dias. Posteriormente, foram mantidas em sombrite $50 \%$ de sombra e a pleno sol, na área de pesquisa experimental da UNIGRAN. Aos 45 e 65 dias após a emergência, as mudas foram pulverizadas com: 1) ácido giberélico $50 \mathrm{mg} . \mathrm{L}^{-1}$; 2) ácido giberélico $100 \mathrm{mg} . \mathrm{L}^{-1}$; e 3) as mudas que não receberam nenhum tratamento serviram como testemunha. Aos 85 dias após a emergência e a cada 15 dias foram avaliados a altura e diâmetro das mudas. Aos 100, 140 e 180 dias após a emergência, as plântulas foram levadas para o Laboratório de Botânica da UFMS, onde se avaliaram a área foliar (AF), com o auxílio de medidor de área foliar LI-COR 3000, massa seca total (MST), da parte aérea (MSPA), das folhas (MSF) e da raiz (MSR); taxa assimilatória líquida (TAL); taxa de crescimento relativo (TCR); e razão de área foliar (RAF) segundo Benincasa (1988). O experimento foi conduzido em delineamento inteiramente casualizado em fatorial 2 (níveis de luz) x 3 (níveis de giberelina) x 3 (idade da muda), em quatro repetições de 15 mudas. Os dados foram analisados pelo teste $\mathrm{F}$, sendo as médias comparadas pelo teste de Tukey a $1 \%$ de probabilidade; aos dados de altura e diâmetro, aplicou-se também a análise de regressão.

R. Árvore, Viçosa-MG, v.30, n.4, p.529-536, 2006 


\section{RESULTADOS E DISCUSSÃO}

As sementes iniciaram a emergência dois dias após a semeadura, entretanto a testemunha e aquelas imersas apenas em água não germinaram no período avaliado. Observa-se na Tabela 1 que não houve diferença significativa entre os tratamentos com escarificação, porém as sementes tratadas com $\mathrm{H}_{2} \mathrm{SO}_{4}+$ água apresentaram emergência 1,25 vez maior, em compararção com a imersão em $\mathrm{KNO}_{3}$.

Não foi observado diferença significativa para o IVE entre os tratamentos, entretanto, as sementes tratadas com $\mathrm{H}_{2} \mathrm{SO}_{4}$ por 5 ' seguidas de imersão em GA apresentaram maior IVE quando comparadas com àquelas tratadas apenas com $\mathrm{H}_{2} \mathrm{SO}_{4}$ por $5^{\prime} \mathrm{e} 10^{\prime}$. Esses resultados são contrários àqueles observados na literatura, em que Bruno et al. (2001) verificaram que, prolongando o tempo de exposição das sementes de sabiá ao $\mathrm{H}_{2} \mathrm{SO}_{4}$ , aumenta a porcentagem de germinação e de vigor e o IVG, embora a massa seca das plântulas não tenha variado significativamente, exceto nas sementes claras e incubadas a $30^{\circ} \mathrm{C}$, as quais apresentaram redução na massa seca. Encontrou-se na literatura que, quanto maior a velocidade de emergência das sementes, menor o tempo de exposição destas a fatores adversos do meio ambiente, os quais podem causar deterioração e até mesmo prejuízo, em termos produtivos. Quanto maior o IVE, maior a velocidade de emergência, o que permite inferir que mais vigoroso é o lote de sementes (NAKAGAWA, 1999).

As plântulas provenientes de sementes escarificadas e tratadas com $\mathrm{KNO}_{3}$ apresentaram maior tamanho de raiz, entretanto não houve diferença no tamanho da parte aérea e nem na massa seca de raiz e parte aérea nos demais tratamentos. Azerêdo et al. (2002) verificaram que a escarificação física das sementes de Achras sapota (sapoti), seguida ou não de embebição, não afetou significativamente o comprimento do hipocótilo e de raiz e o peso de matéria seca da planta.

Não se notou interação significativa entre os fatores luz, tratamento com giberelina e idade da muda para massa seca total, das folhas, da parte aérea e da raiz, altura e diâmetro do colo.

A massa seca das folhas e da parte aérea e a área foliar foram maiores ao final das avaliações quando as mudas se encontravam com 180 dias, sendo maior a pleno sol e não variando entre os tratamentos com giberelina. A área foliar não variou entre os níveis de luz (Tabela 2).

Foi observado interação significativa entre a idade da muda e os tratamentos com GA e luz para massa seca de raiz e massa seca total. A massa seca de raiz foi maior aos 180 dias em todos os tratamentos, entretanto se verificou diferença significativa entre os tratamentos com giberelina e as idades da muda (Tabela 3), sendo maior naquelas crescidas a pleno sol, indicando haver maior disponibilidade de fotoassimilados e maior distribuição nas partes da planta. Segundo Claussen (1996), indivíduos de uma mesma espécie com sistema radicular mais desenvolvido em determinada condição ambiental podem apresentar maior aclimatação do que aqueles com sistema radicular reduzido.

Tabela 1 - Emergência (E), índice de velocidade de emergência (IVE), tamanho da maior raiz (TMR), tamanho da parte aérea (TMPA) e massa seca de raiz (MSR) e de parte aérea (MSPA) de Enterolobium contortisiliqunn. UFMS, Dourados, 2004

Table 1 - Emergence $(E)$, emergence speed index (ESI), root length (LR), length of part aerial (LPA), root dry mass (DMR), aerial part dry mass (DMA) of Enterolobium contortisiliqunn. UFMS, Dourados, 2004

\begin{tabular}{|c|c|c|c|c|c|c|}
\hline Tratamentos & $\mathrm{E}(\%)$ & IVE & TMR $(\mathrm{cm})$ & TMPA $(\mathrm{cm})$ & $\operatorname{MSR}(\mathrm{g})$ & $\operatorname{MSPA}(\mathrm{g})$ \\
\hline Testemunha & $0,00 \mathrm{~B}$ & $0,00 \mathrm{~B}$ & $0,00 \mathrm{D}$ & $0,00 \mathrm{~B}$ & $0,00 \mathrm{~B}$ & $0,00 \mathrm{~B}$ \\
\hline Água/24 h & $0,00 \quad \mathrm{~B}$ & $0,00 \mathrm{~B}$ & $0,00 \mathrm{D}$ & $0,00 \mathrm{~B}$ & $0,00 \mathrm{~B}$ & $0,00 \mathrm{~B}$ \\
\hline $\mathrm{H}_{2} \mathrm{SO}_{4} 5^{\prime}$ & $81,74 \mathrm{~A}$ & $2,46 \mathrm{~B}$ & $6,31 \mathrm{C}$ & $7,16 \mathrm{~A}$ & $0,06 \mathrm{AB}$ & $1,72 \mathrm{~A}$ \\
\hline $\mathrm{H}_{2} \mathrm{SO}_{4} 5^{\prime}+$ Água & $90,21 \mathrm{~A}$ & 3,11 A B & $7,95 \mathrm{BC}$ & $5,95 \mathrm{~A}$ & $0,09 \mathrm{~A}$ & $1,89 \mathrm{~A}$ \\
\hline $\mathrm{H}_{2} \mathrm{SO}_{4}^{4} 5^{\prime}+\mathrm{GA}$ & $84,32 \mathrm{~A}$ & $4,82 \mathrm{~A}$ & $6,10 \mathrm{C}$ & $7,16 \mathrm{~A}$ & $0,08 \mathrm{~A}$ & $1,80 \mathrm{~A}$ \\
\hline $\mathrm{H}_{2} \mathrm{SO}_{4} 5^{\prime}+\mathrm{KNO}_{3}$ & $90,83 \mathrm{~A}$ & 3,03 A B & $9,94 \mathrm{~B}$ & $5,81 \mathrm{~A}$ & $0,07 \mathrm{~A}$ & $1,72 \mathrm{~A}$ \\
\hline $\mathrm{H}_{2} \mathrm{SO}_{4} 10^{\prime}$ & $93,09 \mathrm{~A}$ & $2,82 \mathrm{~B}$ & $6,98 \mathrm{C}$ & $6,43 \mathrm{~A}$ & $0,09 \mathrm{~A}$ & $1,82 \mathrm{~A}$ \\
\hline $\mathrm{H}_{2} \mathrm{SO}_{4} 10^{\circ}+$ Água & $97,74 \mathrm{~A}$ & 3,53 A B & $5,60 \mathrm{C}$ & $6,38 \mathrm{~A}$ & $0,06 \mathrm{AB}$ & $1,83 \mathrm{~A}$ \\
\hline $\mathrm{H}_{2} \mathrm{SO}_{4} 10^{\circ}+\mathrm{GA}$ & $95,51 \mathrm{~A}$ & 3,51 A B & $5,85 \mathrm{C}$ & $7,62 \mathrm{~A}$ & $0,07 \mathrm{~A}$ & $1,73 \mathrm{~A}$ \\
\hline $\mathrm{H}_{2}^{2} \mathrm{SO}_{4}^{4} 10^{\circ}+\mathrm{KNO}_{3}$ & $78,55 \mathrm{~A}$ & 3,09 A B & $13,73 \mathrm{~A}$ & $5,89 \mathrm{~A}$ & $0,08 \mathrm{~A}$ & $1,89 \mathrm{~A}$ \\
\hline $\mathrm{CV}(\%)$ & 7,6 & 23,7 & 12,3 & 21,7 & 32,1 & 8,0 \\
\hline
\end{tabular}

Médias seguidas de mesma letra maiúscula na coluna são estatisticamente iguais entre si, pelo teste de Tukey a $1 \%$ de probabilidade.

R. Árvore, Viçosa-MG, v.30, n.4, p.529-536, 2006 
Tabela 2 - Massa seca de folhas e de parte aérea e área foliar de mudas de Enterolobium contortisiliqunn. Dourados, 2004

Table 2-Leaf and aerial part dry mass and leaf area of Enterolobium contortisiliqunn saplings. Dourados, 2004

\begin{tabular}{llccc}
\hline & & $\begin{array}{c}\text { Massa seca de folhas } \\
(\mathrm{g})\end{array}$ & $\begin{array}{c}\text { Massa seca de parte aérea } \\
(\mathrm{g})\end{array}$ & $\begin{array}{c}\text { Área foliar } \\
\left(\mathrm{dm}^{2}\right)\end{array}$ \\
\hline \multirow{3}{*}{ Idade da muda } & 140 & $1,67 \mathrm{C}$ & $3,36 \mathrm{~B}$ & $125,04 \mathrm{~B}$ \\
& 180 & $2,47 \mathrm{~B}$ & $4,40 \mathrm{~B}$ & $137,92 \mathrm{~B}$ \\
& $5,87 \mathrm{~A}$ & $12,23 \mathrm{~A}$ & $164,28 \mathrm{~A}$ \\
Nível de luz & Pleno Sol & $3,60 \mathrm{~A} *$ & $7,21 \mathrm{~A}$ & $148,18 \mathrm{~A}$ \\
Tratamentos & Testemunha & $3,07 \mathrm{~B}$ & $6,11 \mathrm{~B}$ & $136,64 \mathrm{~A}$ \\
com GA & GA 50 mg.L.-1 & $3,36 \mathrm{~A}$ & $6,61 \mathrm{~A}$ & $139,02 \mathrm{~A}$ \\
& GA 100 mg.L. & $3,21 \mathrm{~A}$ & $6,50 \mathrm{~A}$ & $139,06 \mathrm{~A}$ \\
\hline $\mathrm{CV}(\%)$ & $3,43 \mathrm{~A}$ & $6,87 \mathrm{~A}$ & $149,18 \mathrm{~A}$ \\
\hline
\end{tabular}

Médias seguidas de mesma letra maiúscula na coluna, para cada fator, são estatisticamente iguais entre si, pelo teste de Tukey a $1 \%$ e * pelo teste F.

Tabela 3 - Massa seca de raiz de mudas de Enterolobium contortisiliqunn. Dourados, 2004

Table 3 - Root dry mass of Enterolobium contortisiliqunn saplings. Dourados, 2004

\begin{tabular}{lcccr}
\hline & \multicolumn{4}{c}{ Idade da mudas (dias) } \\
\cline { 2 - 5 } & 100 & 140 & 180 & Média \\
\hline Testemunha & $2,01 \mathrm{Ab}$ & $2,77 \mathrm{Ab}$ & $6,28 \mathrm{Aa}$ & $3,69 \mathrm{~A}$ \\
GA 50 mg. L ${ }^{-1}$ & $3,11 \mathrm{Ab}$ & $3,22 \mathrm{Ab}$ & $5,64 \mathrm{Aa}$ & $3,99 \mathrm{~A}$ \\
GA 100 mg . L ${ }^{-1}$ & $2,35 \mathrm{Ab}$ & $2,46 \mathrm{Ab}$ & $6,74 \mathrm{Aa}$ & $3,85 \mathrm{~A}$ \\
Pleno sol & $2,61 * \mathrm{Ab}$ & $3,04 \mathrm{Ab}$ & $7,17 \mathrm{Aa}$ & $4,27 \mathrm{~A}$ \\
$50 \%$ & $2,37 \mathrm{Ab}$ & $2,59 \mathrm{Ab}$ & $5,27 \mathrm{Ba}$ & $3,41 \mathrm{~B}$ \\
Média & $2,49 \mathrm{~b}$ & $2,82 \mathrm{~b}$ & $6,22 \mathrm{a}$ & \\
\hline
\end{tabular}

$\mathrm{CV}(\%)=22,6$

Médias seguidas de mesma letra minúscula na linha e maiúscula na coluna, para cada fator, são estatisticamente iguais entre si, pelo teste de Tukey a $1 \% \mathrm{e}^{*}$ pelo teste F.

Notou-se diferença significativa na massa seca total das mudas apenas aos 180 dias de idade quando tratadas com GA100 mg.L-1 (Tabela 4). Quanto ao sombreamento, em média, as mudas crescidas a pleno sol apresentaram maior massa seca total. Resultados semelhantes foram observados em Schefflera morototoni (mandiocão) (Mazzei et al., 1998), Croton urucurana (sangra-d’água), Guazuma ulmifolia (mutambo), Peltophorum dubium (canafístula), Lonchocarpus muehlbergianus (feijão-cru) e Tabebuia impetiginosa (ipê-rosa) (MORAIS NETO et al., 2001).

Não foi observada interação significativa entre os tratamentos de luz e giberelina com a idade da muda para os parâmetros altura e diâmetro. A altura a pleno sol (média de $51,94 \mathrm{~cm}$ ) foi maior comparada com aquelas crescendo sob 50\% de sombreamento (média de 49,51 $\mathrm{cm}$ ). A altura apresentou um crescimento linear, alcançando ao final do experimento valores de 99,19 cm (dados observados) (Figura 1). O diâmetro não variou significativamente entre os níveis de luz, apresentando em média $1,32 \mathrm{~cm}$ e um crescimento linear que atingiu, ao final do experimento, $1,83 \mathrm{~cm}$.

Resultados semelhantes quanto a diâmetro de colo foram observados por Almeida et al. (2004) em Cryptocaria aschersoniana (canela-de-batalha), Scalon e Alvarenga (1993) em Platycyamus regnelli (pau-pereira), Scalon et al. (2002) em Caesalpinia peltophoroides ( sibipiruna) e Inga edulis (ingá), Scalon et al. (2003) em Bombacopsis glabra (castanha-do-maranhão).

Tabela 4 - Massa seca total de mudas de Enterolobium contortisiliqunn. Dourados, 2004

Table 4 - Total dry mass of Enterolobium contortisiliqunn saplings. Dourados, 2004

\begin{tabular}{lcccc}
\hline & \multicolumn{5}{c}{ Idade da mudas (dias) } \\
\cline { 2 - 5 } & 100 & 140 & 180 & Média \\
\hline Testemunha & $5,50 \mathrm{Ab}$ & $7,47 \mathrm{Ab}$ & $17,92 \mathrm{ABa}$ & $10,86 \mathrm{~A}$ \\
GA $50 \mathrm{mg} \cdot \mathrm{L}^{-1}$ & $5,61 \mathrm{Ab}$ & $6,53 \mathrm{Ab}$ & $17,06 \mathrm{Ba}$ & $10,49 \mathrm{~A}$ \\
GA $100 \mathrm{mg} \cdot \mathrm{L}^{-1}$ & $5,35 \mathrm{Ab}$ & $6,84 \mathrm{Ab}$ & $20,38 \mathrm{Aa}$ & $10,29 \mathrm{~A}$ \\
Pleno sol & $6,01 * \mathrm{Ac}$ & $8,22 \mathrm{Ab}$ & $20,55 \mathrm{Aa}$ & $11,59 \mathrm{~A}$ \\
$50 \%$ & $5,61 \mathrm{Ab}$ & $6,53 \mathrm{Ab}$ & $16,36 \mathrm{Ba}$ & $9,50 \mathrm{~B}$ \\
Média & $5,81 \mathrm{c}$ & $7,38 \mathrm{~b}$ & $18,45 \mathrm{a}$ & \\
\hline CV $(\%)=16,9$ & \multicolumn{5}{c}{} \\
\hline
\end{tabular}

Médias seguidas de mesma letra minúscula na linha e maiúscula na coluna, para cada fator, são estatisticamente iguais entre si, pelo teste de Tukey a $1 \%$ e * pelo teste F.

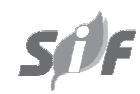

R. Árvore, Viçosa-MG, v.30, n.4, p.529-536, 2006 
Com relação à altura, os resultados coincidiram com os observados por Souza e Silva (1999) em Cabralea cangerana (canjarana) e por Scalon et al. (2001) em Eugenia uniflora (pitanga).

TAL, RAF e TCR não variaram entre os níveis de luz e tratamentos com GA (Tabela 5). Com relação à luminosidade, resultados semelhantes foram verificados por Scalon et al. (2003) em Bombacopsis glabra.

Os tratamentos com giberelina não se mostraram eficientes em acelerar a germinação e nem o crescimento da plântula. Resultados semelhantes foram obtidos por Stefanini et al. (2003), trabalhando com reguladores de crescimento em Lippia alba (erva-cidreira), as quais observaram, em sua revisão, efeito significativo da GA sobre o crescimento das plantas; justificam seus resultados as concentrações dos fitorreguladores empregados por eles. Os resultados do presente trabalho foram contrários às informações da literatura - ressaltando o efeito da GA sobre o alongamento celular e crescimento - e podem ser atribuídos também às concentrações da giberelina empregadas.

$\begin{array}{lrr}* \text { Altura }=-36.813954+0.636621 x ; & -r 2=0,90 \\ \Delta \text { Diâmetro }=0.204413+0.0080783 x ; & -r 2=0,97\end{array}$

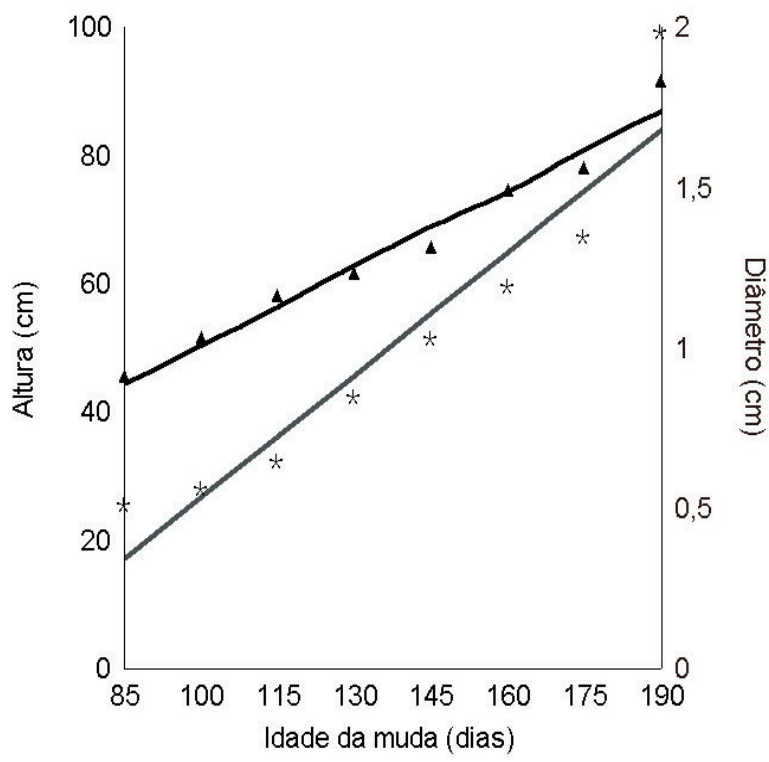

Figura 1 - Altura e diâmetro das mudas de Enterolobium contortisiliquun. Dourados, 2004.

Figure 1- Height and diameter of Enterolobium contortisiliquun saplings. Dourados, 2004.

R. Árvore, Viçosa-MG, v.30, n.4, p.529-536, 2006
Tabela 5 - Taxa assimilatória líquida (TAL), razão de área foliar (RAF) e taxa de crescimento relativo (TCR) de mudas de Enterolobium contortisiliquun. Dourados, 2004

Table 5 - Net assimilating rate (NAR), leaf area ratio (LAR) and relative growth rates $(R G R)$ of Enterolobium contortisiliquun saplings. Dourados, 2004

\begin{tabular}{lccc}
\hline Tratamentos & $\begin{array}{c}\text { TAL } \\
\left(\mathrm{g} \mathrm{x} \mathrm{dm}^{2} \times \mathrm{g}^{-1}\right)\end{array}$ & $\begin{array}{c}\mathrm{RAF} \\
\left(\mathrm{dm}^{2} \times \mathrm{g}^{-1}\right)\end{array}$ & $\begin{array}{c}\text { TCR } \\
\left(\mathrm{g} \mathrm{x} \mathrm{g} \mathrm{x} \mathrm{dia-1}^{-1}\right.\end{array}$ \\
\hline Pleno Sol & $0,00112 \mathrm{~A}$ & $8,2296 \mathrm{~A}$ & $0.0152 \mathrm{~A}$ \\
50\% de & $0,00098 \mathrm{~A}$ & $8,4193 \mathrm{~A}$ & $0.0129 \mathrm{~A}$ \\
sombreamento & & & \\
Testemunha & $0,00113 \mathrm{~A}$ & $8,6878 \mathrm{~A}$ & $0.0145 \mathrm{~A}$ \\
GA 50 mg . L & $0,00082 \mathrm{~A}$ & $8,1308 \mathrm{~A}$ & $0.0117 \mathrm{~A}$ \\
GA 100 mg . L & $0,00122 \mathrm{~A}$ & $8,1547 \mathrm{~A}$ & $0.0160 \mathrm{~A}$ \\
\hline CV $=(\%)$ & 20,5 & 22,4 & 19.9 \\
\hline
\end{tabular}

Médias seguidas de mesma letra minúscula na coluna, para cada fator, são estatisticamente iguais entre si, pelo teste de Tukey a $1 \%$ e * pelo teste F.

\section{CONCLUSÃO}

Considerando a variação de respostas e o custo/ benefício, a escarificação por $10^{*}$ pode ser indicada como o tratamento mais adequado para a germinação das sementes de orelha-de-macaco. No período avaliado, as mudas se desenvolveram melhor a pleno sol, apresentando maior altura, MSF, MSPA e MSR. Os tratamentos com GA, nas doses utilizadas, não interferiram no crescimento das mudas.

\section{AGRADECIMENTO}

À FUNDECT, pelo apoio financeiro.

\section{REFERÊNCIAS BIBLIOGRÁFICAS}

ALMEIDA, L.P. et al. Crescimento inicial de plantas de Cryptocaria aschersoniana Mez. submetidas a níveis de radiação solar. Ciência Rural, v. 34, n. 1, p. 83-88, 2004.

AZERÊDO, G.A. et al. Desempenho de sementes de sapoti (Achras sapota L.) submetidas a diferentes tratamentos pré-germinativos.

Revista Brasileira de Fruticultura, v. 24, n. 1, p. 147-150, 2002.

BENINCASA, M. M. P. Análise de crescimento de plantas (noções básicas), Jaboticabal:Universidade Estadual de São Paulo, 1988.41p. 
BEWLEY, J.D.; BLACK, M. Seeds: physiology of development and germination. New York: Plenum Press, 1994. 445p.

BEWLEY, J.D. Breaking dow the walls: a role for endo betamananase in release from seed dormancy. Trend in Plant Science, v. 2, p. 139-144, 1997

BRUNO, R.L.A. et al. Tratamentos pré-germinativos para superar a dormência de sementes de Mimosa caesalpiniaefolia Benth. Revista Brasileira de Sementes, v. 23, n. 2, p. 136-143, 2001.

CARVALHO, N. M.; NAKAGAWA, J. Sementes: ciência, tecnologia e produção. Jaboticabal: FUNEP, 2000. 588 p.

CLAUSSEN, J.W. Acclimatation abilities of three tropical rainforest seedlings to an increase in light intensity. Forest Ecology and Management, Amsterdam, v. 80, n. 1/3, p. 245-255, 1996.

DANIEL, O.; OHASHI, S.T.; SANTOS, R.A. Produção de mudas de Goupia glabra (Cupiúba): efeito de níveis de sombreamento e tamanho de embalagens. Revista Árvore, v. 18, n. 1, p. 1-13, 1994.

ERIG, P.R.; FERREIRA, G.; MORO, E. Crescimento inicial de plantas de fruta-dO-conde sob efeito do ácido giberélico. In: CONGRESSO BRASILEIRO DE FISIOLOGIA VEGETAL, 8., 2001, Ilhéus. CD-ROM.

GARCIA, J. et al. Efeito de tratamentos para acelerar a germina;ao de sementes de anileira (Indigofera suffruticosa). Pesquisa Agropecuária Tropical, v. 30, n. 2, p. 55-57, 2000.

HILHORST, H.W.M.A. A critical update on seed dormancy. I.Primary dormancy. Seed Science Research, v. 5, p. 61-73, 1998 .

JÉLLER, H.; PEREZ, S.C.J.G.A A. Dormência e temperatura em sementes de Cassia excelsa 1999), Revista Brasileira de Sementes, v. 21, n. 1, p. 41-45, 1999.

KERBAUY,G.B. Fisiologia vegetal. Rio de Janeiro: Guanabara Koogan, 2004. 452p.

KOOENNEEF, M.; BENTSINK, L.; HILHORST, H. Seed dormancy and germination. Current Opinion in Plant Biology, v. 5, p. 33-36, 2002.
LOPES, J.C; PEREIRA, M.D.; MARTINS-FILHO, S. Germinação de sementes de Calabura (Muntingia calabura L.). Revista Brasileira de Sementes, v. 24, n. 1, p. 59-66, 2002.

MATO GROSSO DO SUL Secretaria de Planejamento e Coordenação Geral. Atlas Multireferencial. Campo Grande: 1990. 28p.

MAZZEI, L. J. et al. Crescimento de plântulas de Schefflera morototoni (Aubl.) Maguire, Steyermark e Frodin em diferentes níveis de sombreamento no viveiro. Boletim do Herbário Ezechias Paulo Heringer, v. 3, p. 27-36, 1998.

MORAIS NETO, S.P. et al. Crescimento de mudas de algumas espécies arbóreas que ocorrem na mata atlântica em função do nível de luminosidade. Revista Árvore, v. 24, n. 1, p. 35-45, 2001.

NAKAGAWA, J. Testes de vigor baseados no desempenho das plântulas In: KRZYZANOWSKI, F.C.; VIEIRA, R.D.; FRANÇA NETO, J.B. Vigor de sementes: conceitos e testes. Londrina:Abrates, 1999.p. 2.1-2.24.

POPINIGS, F.. Fisiologia da semente. Brasília: Agiplan, 1985. 289p.

PENG, J.; HARBERD, N.P. The role of GAmediated signlling in the control of seed germination. Current Opinion in Plant Biology, v.5, p. 376-381, 2002.

PORTELA, R.C.Q.; SILVA, I.L.; PINÃ-RODRIGUES, F.C.M. Crescimento inicial de mudas de Clitória fairchildiana Howard e Peltophorum dubium (Sprenge) Taub em diferentes condições de sombreamento. Ciência Florestal, v. 11, n. 2, p. 163-170, 2001.

SCALON, S.P.Q.; ALVARENGA, A.A. Efeitos do sombreamento sobre a formação de mudas de pau-pereira (Platycyamus regnelli BENTH.). Revista Árvore, v. 17, n. 3, p. 265-270, 1993.

SCALON, S.P.Q. et al. Germinação e crescimento de mudas de pitangueira (Eugenia uniflora L.) sob condições de sombreamento. Revista Brasileira de Fruticultura, v. 23, n. 3, p. 652-655, 2001.

SCALON, S.P.Q.; MUSSURY, R.M.; VERALDO, F. Crescimento inicial de mudas de espécies florestais nativas sob diferentes níveis de sombreamento. Revista Árvore, v. 26, n. 1, p. 1-5, 2002.

R. Árvore, Viçosa-MG, v.30, n.4, p.529-536, 2006 
SCALON, S.P.Q.; MUSSURY, R.M.; SCALON FILHO, H. Crescimento inicial de mudas de Bombacopsis glabra (Pasq.) A. Robyns sob diferentes níveis de sombreamento. Revista Árvore, v. 27, n. 6, p. 753-758, 2003.

SMIDERLE, O.J.; SOUZA, R.C.P. Dormência em sementes de paricarana (Bowdichia virgilioides Hunth - Fabaceae - Papilionidae). Revista Brasileira de Sementes, v.25, n.1, p.72-75, 2002.

SOUSA-SILVA, J. C. et al. Desenvolvimento inicial de Cabralea canjerana Saldanha em diferentes condições de luz. Boletim do Herbário Ezechias Paulo Heringer, v. 4 p .80-89, 1999.
STEFANINI, M.B.; RODRIGUES, S.D.; MING, L.C. Ação de fitorreguladores no crescimento da ervacidreira-brasileira. Horticultura brasileira, v. 20, n. 1, p.18-23, 2002.

ZAIDAN, L.B.P.; BARBEDO, C.J. Quebra de dormëncia em sementes. In: FERREIRA, A.G.; BORGHETTI, F. (Org.) Germinação: do básico ao aplicado. São Paulo: Artmed, 2004. 323p.

ZAYAT, A.G.; RANAL, M.A. Germinação de sementes de capiçova. Pesquisa Agropecuária Brasileira, v. 32, p. $1205-1213,1997$. 